LEARNING TO ARGUE ONLINE: SCRIPTED GROUPS SURPASS INDIVIDUALS (UNSCRIPTED GROUPS DO NOT)

This is a post -print of an article submitted for consideration in the Computers in Human Behavior (C) 2010 Elsevier.

Personal use of this manuscript is permitted. Permission from Elsevier must be obtained for any other commercial purpose.

This article may not exactly replicate the published version, due to editorial changes and/or formatting and corrections during the final stage of publication. Interested readers are advised to consult the published version which can be found at:

http://www.sciencedirect.com/science/article/pii/S0747563209001381

doi: $\{10.1016 /$ j.chb.2009.08.007 \}

Please refer this manuscript as:

Weinberger, A., Stegmann, K., \& Fischer, F. (2010). Learning to argue online: Scripted groups surpass individuals (unscripted groups do not). Computers in Human Behavior.26(4), 506-515. 
Running head: LEARNING TO ARGUE ONLINE

Learning to argue online: Scripted groups surpass individuals (unscripted groups do not)

\author{
Armin Weinberger* \\ University of Twente
}

Karsten Stegmann \& Frank Fischer

Ludwig-Maximilians-Universität (LMU) München

${ }^{*}$ Correspondence can be sent to Armin Weinberger, University of Twente, Faculty of Behavioural Sciences, Department of Instructional Technology, P.O. Box 217, 7500 AE Enschede, The Netherlands. Phone: ++31-53-4895308, Fax: ++ 31-53-4892849, E-mail: A.Weinberger@utwente.nl 


\begin{abstract}
Students often face process losses when learning together via text-based online environments. Computer-supported collaboration scripts can scaffold collaborative learning processes by distributing roles and activities and thus facilitate acquisition of domain-specific as well as domain-general knowledge, such as knowledge on argumentation. Possibly, individual learners would require less additional support or could equally benefit from computersupported scripts. In this study with a $2 \times 2$-factorial design $(N=36)$ we investigate the effects of a script (with versus without) and the learning arrangement (individual versus collaborative) on how learners distribute content-based roles to accomplish the task and argumentatively elaborate the learning material within groups to acquire domain-specific and argumentative knowledge, in the context of a case-based online environment in an Educational Psychology higher education course. A large multivariate interaction effect of the two factors on learning outcomes could be found, indicating that collaborative learning outperforms individual learning regarding both of these knowledge types if it is structured by a script. In the unstructured form, however, collaborative learning is not superior to individual learning in relation to either knowledge type. We thus conclude that collaborative online learners can benefit greatly from scripts reducing process losses and specifying roles and activities within online groups.
\end{abstract}

Keywords: CSCL, collaborative learning, individual learning, online learning, collaboration scripts, argumentative knowledge construction 


\section{LEARNING TO ARGUE ONLINE: SCRIPTED GROUPS SURPASS INDIVIDUALS}

\section{(UNSCRIPTED GROUPS DO NOT)}

Command of argumentative skills has been regarded an important competency as well as an important component of science education (Erduran \& Jiménez-Aleixandre, 2007). Students are supposed to learn to participate in argumentative discourse in the respective scientific fields. In particular, students should be able to warrant and qualify their claims and to draw inferences on complex, open-ended problems based on theory and observations. Regular seminar settings, however, rarely foresee opportunities for students to equally participate in what has been termed argumentative knowledge construction (AKC; e.g., Weinberger \& Fischer, 2006). AKC is an approach that describes the acquisition of domainspecific and argumentative knowledge through the elaboration of the learning material by constructing and reviewing arguments. Some studies indicate that text-based online learning environments facilitate equal participation in $\mathrm{AKC}$ by allowing students to take the time and resources they need to construct elaborated arguments (Marttunen \& Laurinen, 2001; Schellens \& Valcke, 2006).

Argumentative elaboration activities, such as examining evidence and reasoning for one claim or another, may sometimes impede task performance or range of task aspects being covered, i.e. the quality and extent to which groups or individuals can solve a problem. However, argumentative elaboration activities are considered to be strongly linked to individual knowledge acquisition, i.e. the amount of knowledge that learners can transfer from a collaborative or individual learning phase to a later point in time as a residue in the learners' individual minds (Baker, 2003; Nussbaum, 2008). Accordingly, it is a challenge to scaffold learners in accomplishing challenging argumentative tasks and simultaneously, to problematise aspects of the tasks, e.g. through prompting learners to provide evidence for 
their claims or to identify counter-arguments to a specific problem solution, which might otherwise be overlooked (Asterhan \& Schwarz, 2007; Reiser, 2004).

AKC can be arranged as a collaborative or individual activity. After years of research on prior conditions of these different learning arrangements (see Slavin, 1993), the focus of research on learning in groups has shifted to analysis of processes of collaborative learning (Dillenbourg, Baker, Blaye, \& O’Malley, 1995). We argue that by analysis and facilitation of the processes of individual and collaborative learners light can be shed on how collaborative learners distribute roles and activities in $\mathrm{AKC}$ and how they can be facilitated to do so in comparison to individual learners who take over all necessary roles and activities themselves. In addition to analysis of group level phenomena (e.g., Weinberger, Stegmann, \& Fischer, 2007), zooming in on the individual learner's experiences in collaborative learning arrangements can elucidate how collaborative interaction is related to individual knowledge acquisition (Salomon, 1993; Weinberger, Stegmann, \& Fischer, 2008). In the following paragraphs, we will discuss $\mathrm{AKC}$ in collaborative and individual online learning environments and its effects on task performance and knowledge acquisition. Subsequently, we present how collaborative learners distribute the task over content-based roles in contrast to individual learners in online learning environments. Finally, we examine how AKC can be facilitated through an argumentative script implemented in the interface of online learning environments.

Argumentative knowledge construction in collaborative learning arrangements

In contrast to regular seminar settings, collaborative learning arrangements, in which learners in small groups jointly work on learning tasks without teacher interventions (Cohen, 1994) bear possibilities for every student involved to exercise argumentative elaboration activities (cf. Cohen \& Lotan, 1995; Hsi \& Hoadley, 1997; Van Boxtel, Van der Linden, \& Kanselaar, 2000). Collaborative learning has been ascribed added value in comparison to 
individual learning with regard to fostering both, domain-specific and domain-general knowledge, such as argumentative knowledge (e.g., Johnson \& Johnson, 1992). With respect to both types of learning outcomes, collaborative learning has shown to be more effective than individual learning if learners share a goal, positively depend on each other to solve the task, and are individually accountable for their contributions, which could be attained by specific task and incentive structures (Johnson \& Johnson, 1992; Slavin, 1993). Collaborative learners depend on each other to a larger degree in complex, open-ended tasks, which consequently have been termed "true group tasks" (Cohen, 1994, p. 3). Explanations for advantages of collaborative over individual learning from complex tasks are often based on the idea that collaborative learners can use their learning partners as an additional resource (Fischer, 2002). Learning partners can be regarded as additional learning resources when contributing unshared prior knowledge to the discussion, which may eventually be shared after learning together and thus, facilitate learners to take over multiple perspectives on the problem (Weinberger et al., 2007).

Beyond sharing and benefitting from each other's knowledge, collaborative learners can mutually elicit argumentative elaboration and thus foster multi-perspective, applicationrelated, transferable as well as argumentative knowledge (e.g., Johnson \& Johnson, 1992; Leitão, 2000; Schwarz, Neuman, \& Biezuner, 2000). Learning partners may share a focus on a limited range of task aspects and as a collective information processing system put more processing capacity into use when tackling complex tasks (Hinsz, Tindale, \& Vollrath, 1997; Kirschner, Paas, \& Kirschner, 2009). Kirschner and colleagues (2009), for instance, found an interaction effect between the learning arrangement (individual versus collaborative) and the type of test (retention versus transfer) with respect to efficiency, which was measured by a ratio of effort invested and outcomes in a retention and a transfer test. Results of this study indicate that groups of learners outperform individual learners in efficiency on transfer tests 
whereas individual learners perform more efficiently on a retention test. These results indicate that group learning has advantages over individual learning from complex tasks regarding acquisition of transferable knowledge. Still, individual learning appears to be superior for efficiently recalling concepts and facts.

Computer-supported collaborative learning (CSCL) scenarios in particular have been argued to facilitate equal participation in argumentative discourse as students could use additional online resources and tools to construct and represent elaborated arguments at their own pace (Andriessen, Baker, \& Suthers, 2003; Hsi \& Hoadley, 1997; Kirschner, Buckingham Shum, \& Carr, 2003; Marttunen \& Laurinen, 2001; Munneke, Andriessen, Kanselaar, \& Kirschner, 2007; Scardamalia \& Bereiter, 1996; Schellens \& Valcke, 2006; Veerman, 2003). However, computer-supported collaborative learners frequently suffer from process losses when distributing roles and activities in online environments (Strijbos, Martens, Jochems, \& Broers, 2004), e.g. because learning partners dominate the debate and block production of arguments (see Meijas, 2007), or have difficulties to engage in meaningful learning activities such as constructing arguments and counterarguments when learning together (Marttunen \& Laurinen, 2001). These problems may take different shapes depending on communication modalities, such as synchronicity, code, and anonymity, within specific CSCL environments in contrast to individual online learning (Weinberger \& Mandl, 2003).

Argumentative knowledge construction in individual learning arrangements Individual learners in online environments obviously do not suffer from CSCL process losses. Moreover, students have been regarded to be in general more familiar with individual learning environments, in which learners tackle learning tasks and coordinate learning resources in a self-guided manner without teacher interventions (Mandl, Gruber, \& Renkl, 1996). Groups of learners often realise a suboptimal distribution of complementary 
roles, such as the 'sucker' and 'free-rider' (Kerr, 1983), i.e. one learner covering major parts of the task and other learners reducing their task engagement (see also Strijbos \& De Laat, this issue). This suboptimal distribution of roles in groups of learners can tremendously reduce the potential of collaborative learning for equal participation in argumentative elaboration activities (Cohen \& Lotan, 1995). In contrast, individual learners are supposed to autonomously cover all aspects of a learning task in an active and self-regulated manner and thereby exercise argumentative learning activities at their own pace, without processes losses emerging as in collaborative scenarios.

Possibly, students may be better off to learn how to argue in individual learning environments, as learning to argue does not need to be conceptualised as a genuinely collaborative activity (Kuhn, 1991; Voss \& Van Dyke, 2001). A meta-analysis shows that computer support has positive effects on individual writing with respect to quantity and quality of students' essays (Goldberg, Russel, \& Cook, 2003). Computer-supported individual essay writing may be also particularly preferable to computer-mediated collaborative writing scenarios, which typically lacks the interactivity and expressiveness collaborative learners require to coordinate themselves (e.g., Quinn, Mehan, Levin, \& Black, 1983). Research on computer-supported collaborative work (CSCW) likewise shows that computer-mediated groups have difficulties to respond immediately and to convey ideas without using para- and nonverbal social context cues, which might hamper task performance of the group, i.e. jointly meeting the solution criteria of a problem (Barile \& Durso, 2002; Galegher \& Kraut, 1990; Kraut, Galegher, Fish, \& Chalfonte, 1992; Tammaro, Mosier, Goodwin, \& Spitz, 1997).

Summing up, individual learning arrangements may have specific advantages over collaborative learning - especially regarding recall of concepts and facts - although individual learners cannot build on learning partners as additional resources for sharing 
knowledge and facilitating argumentative elaboration. To foster specific learning outcomes beyond recall of concepts and facts, there is some empirical evidence that learners should be challenged to collaboratively learn from solving complex tasks with the diverse knowledge within a small group serving as an additional resource (Fischer, 2002; Weinberger et al., 2007). Collaborative learning can exceed individual learning with respect to acquisition of argumentative skills and application-related domain knowledge (e.g., Stegmann, Weinberger, \& Fischer, 2007). Whether students can derive an advantage from learning in groups may depend on how well they manage to reduce group processes losses and engage in meaningful learning activities together, such as argumentative elaboration of the learning material.

Distribution of content-based roles and task performance

How can learners overcome the aforementioned barriers and tap into the potential of collaborative learning? One of the crucial factors for task performance of groups is how prior knowledge is distributed within a group (Klimoski \& Mohammed, 1994). Complex tasks have been regarded as true group tasks (Cohen, 1994), because more complex tasks require more diverse resources distributed in groups and located in the individual minds of group members (Hinsz et al., 1997). In relation to how prior resources are distributed in a group, a complex task may be divided into sub-tasks that are taken over by individual group members. This has been termed distribution of content-based roles and activities (Strijbos et al., 2004) and considered crucial for task performance of groups (Hinsz et al., 1997). For instance, in knowledge-heterogeneous dyads a tutor-tutee role distribution may emerge spontaneously and improve learning outcomes compared to knowledge-homogeneous groups (Fischer, 2001). Depending on how collaborative learners distribute content-based roles and activities, they may also cover a smaller or larger range of task aspects, i.e. the amount of sub-tasks, in which complex tasks could be decomposed, and in this way realise more or less learning opportunities (Weinberger et al., 2007). Thus, the range of task aspects that collaborative 
learners cover can be considered as an indicator for the distribution of content-based roles. Groups have the potential to argumentatively elaborate multiple perspectives on a large range of task aspects. However, groups rarely tap that potential. Collaborative learners have difficulties to effectively distribute roles and tend to quickly converge on and accentuate individual group members' specific task focus and approach (see Hinsz et al., 1997), e.g. particular misconceptions of individual group members are potentially emphasised in group work. Task aspects covered by group members also need to be shared within the group. In this respect, the range of task aspects covered by the group versus the aspects covered by an individual group member needs to be differentiated and compared to the range of task aspects of learners in individual learning arrangements.

Task performance and individual knowledge acquisition There are indications that task performance may not always predict individual knowledge acquisition well (Webb, 1993; Weinberger, Fischer, \& Mandl, 2003). In the study by Weinberger and colleagues (2003), collaborative learners were prompted to answer a sequence of content-related questions, which facilitated learners' task performance - in this case analysing specific problem cases. However, the prompted learners acquired less application-related knowledge as a result of this learning experience than learners who were not prompted to answer questions. Vice versa, groups that were scaffolded with interactionoriented prompts to engage in specific complementary conflict-oriented roles acquired more knowledge individually without improving task performance of the group. These results indicate that specific role distributions and argumentative behaviour of students may be better predictors for learning than task performance measures (Weinberger et al., 2008; Webb, 1989, 1993). In Webb's study (1993), students' interaction pattern was a better predictor for individual learning outcome than performance in the group setting only. Trying to understand and apply the help received from peers has been shown to be a particularly effective learning 
strategy. In contrast, copying other students' work or receiving assistance without aiming to understand how to solve the task by oneself may lead learners to perform well on a task at hand, but impede individual knowledge acquisition.

These findings call for a differentiation between task performance and the argumentative elaboration of the learning material, with the latter being hypothesised to be causally related to individual knowledge acquisition (e.g., Baker, 2003). Moreover, these findings call for further analysis and facilitation of processes and outcomes of individual and collaborative learning. One important process aspect of AKC is individual self-explanation of the learning material when constructing arguments. Inter-individual process aspects of AKC are distributing content-based roles, being confronted with and trying to understand peers' diverging conceptualisations of a problem, and constructing arguments and counterarguments about a complex problem in discourse (Andriessen et al., 2003; Baker, 2003; Clark, Sampson, Weinberger, \& Erkens, 2007; Leitão, 2000; Stegmann et al., 2007; Weinberger \& Fischer, 2006). Research in this area is challenging because social and cognitive processes are highly intertwined. Investigating the learning arrangement more specifically could aim at questions on how individual and collaborative learners can be supported to solve complex problems and engage in specific argumentative activities as well as to acquire individual domainspecific and domain-general knowledge (such as argumentative knowledge).

Facilitating individual and collaborative learning with computer-supported collaboration scripts

One approach that has been successfully applied to CSCL is scripted collaboration (Fischer, Kollar, Haake, \& Mandl, 2007; O’Donnell, 1999; O’Donnell \& Dansereau, 1992). Computer-supported scripts specify, sequence, and assign roles and activities to learners. Scripts may effectively structure different aspects of learners' interactions, e.g. the content quality or the formal structure of argumentation. Scripting CSCL induces specific patterns of 
learner interactions and facilitates learning outcomes beyond what could be achieved with unstructured CSCL (e.g., Weinberger, Stegmann, Fischer, \& Mandl, 2007). For instance, a script distributing the roles of case analyst and critic and including rotation of these roles facilitated specific interaction patterns as well as learning outcomes (Weinberger, Ertl, Fischer, \& Mandl, 2005). Scripts appear to particularly foster domain-general knowledge, such as argumentative knowledge (Kollar, Fischer, \& Slotta, 2007; Stegmann et al., 2007) or interdisciplinary communication competencies (Rummel \& Spada, 2007) - typically not at the expense of domain-specific knowledge acquisition. Also, collaborative writing research indicates that computer-supported collaborative writers can be successfully scaffolded by prompts and socio-cognitive structuring (Yarrow \& Topping, 2001). It seems to be particularly effective to instruct writers to compose a text individually, but revise the text together with a peer (Veerman \& Treasure-Jones, 1999; Zammuner, 1995).

Apparently, scripts can orchestrate individual and collaborative phases in environments comprising both learning arrangements as well as facilitate learners to engage in specific discourse activities. The ways in which scripts induce specific learning activities may be manifold (Weinberger, Kollar, Dimitriadis, Mäkitalo-Siegl, \& Fischer, 2009). Scripts may change expectations of learners to what degree they or their learning partners may need to cognitively elaborate the learning material. Scripts may thus effectively distribute specific roles and important learning processes over a group of learners (O’Donnell, 1999; De Wever, Van Keer, Schellens, \& Valcke, this issue). By defining roles and a sequence of activities as well as changing expectations, scripts can reduce process losses typically experienced by computer-supported collaborative learners, such as coordination problems (e.g., Strijbos et al., 2004). Script effects may also be due to their support of meaningful learning activities by the individual learner, such as sound argument construction and elaboration of the learning materials (Weinberger, Stegmann, Fischer, \& Mandl, 2007). There are clear indications that 
scripts can facilitate argumentative activities and acquisition of argumentative knowledge of collaborative learners beyond what unscripted collaborative learners could achieve (Kollar et al., 2007). Improving argument construction facilitates learning twofold: a) during the process of composing an argument, and b) when an argument is heard or read by the learning partners. Improved arguments may thus increase chances that learners would be able to acknowledge multiple peer perspectives on learning tasks, elaborate the learning material, and acquire knowledge. Scripts focusing on argumentative elaboration activities may problematise the learning task and thereby foster argumentative elaboration and knowledge acquisition, but impede task performance (see Reiser, 2004).

Although the scripting approach has been developed to support small groups, scripts often aim to facilitate individual learners' specific activities, e.g. the production of single arguments. Scripts guiding individual learners with process-oriented scaffolds without distributing different roles and activities over a group of learners have also been termed schemata (e.g., Ertl, Fischer, \& Mandl, 2006). Thus, scripts facilitating argument construction rather than distributing activities and orchestrating social interaction could also be applied in individual learning arrangements guiding learners to engage in specific activities in a specific sequence. The question is whether scripts would facilitate individual learners as well as groups regarding process aspects (i.e., task performance, range of task aspects being covered and argumentative elaboration) and outcomes of $\mathrm{AKC}$ (i.e., acquisition of domain-specific and argumentative knowledge). Scripts may facilitate specific learning activities regardless of individual or collaborative learning arrangement, but might be particularly effective in collaborative learning arrangements, because they would additionally reduce process losses of group learning (e.g., Pfister, 2005).

\section{Research questions}


$R Q 1$ focuses on process aspects of computer-supported learning (namely task performance, range of task aspects being covered, and argumentative elaboration of the learning material) and investigates to what extent these processes can be affected by a script (with versus without), the learning arrangement (individual versus collaborative), and the combination thereof. Based on consistent findings that scripts can induce specific interaction patterns as well as facilitate specific learning activities (Fischer et al., 2007), we hypothesise that the script would positively affect argumentative elaboration, but impede task performance and the range of task aspects that are being covered in individual and collaborative computer-supported learning. We further hypothesise that individual learners would outperform collaborative learners regarding all of these process aspects in text-based computer-supported environments. For instance, groups would distribute content-based roles with group members each covering a smaller range of task aspects, as compared to individual learners who are assumed to cover a larger range of task aspects. This hypothesis is based on earlier findings of groups being inferior to individuals, e.g. in solving complex tasks in textbased environments (Barile \& Durso, 2002; Galegher \& Kraut, 1990). As scripts provide learners with a clear structure of what to do, scripts may have particularly beneficial effects for collaborative learners, who otherwise suffer from process losses in contrast to individual learners, whereas individual learners cannot build on this script advantage.

The focus of $R Q 2$ is on learning outcomes and investigates to what extent a script (with versus without), the learning arrangement (individual versus collaborative), and the combination thereof affect individual acquisition of domain-specific, application-related knowledge and argumentative knowledge. We hypothesise that the script would foster individual acquisition of domain-specific and argumentative knowledge of collaborative learners beyond levels that unscripted collaborative or individual learners would attain as has been shown before (Fischer et al., 2007; Stegmann et al., 2007; Weinberger et al., 2005; 
Rummel \& Spada, 2007). Possibly, the script could reduce process losses of collaborative learners to the extent that collaborative learners would benefit more than individual learners regarding individual acquisition of domain-specific and argumentative knowledge. In line with prior research, we hypothesise that collaborative learners outperform individual learners when learning from complex tasks with regard to acquisition of application-related domainspecific and argumentative knowledge (Cohen, 1994; Fischer, 2002; Kirschner et al., 2009). Methods

\section{Participants}

Seventy-two students of an one hour introductory lecture plus a two hours course of educational science at the Ludwig-Maximilians-Universität München (LMU) participated in this study. Participation was mandatory to obtain a course credit, but the outcomes within the study were not included in overall grading.

\section{Design}

In a $2 \times 2$-factorial design, we investigated the effects of an argumentative script (with versus without) and the learning arrangement (individual versus collaborative) on learning processes and outcomes of $\mathrm{AKC}$ in the context of a computer-supported learning environment in higher education.

The three hour online learning session was to complement a lecture plus seminar on standard curriculum content, which was attribution theory of Weiner (1985). Students were individually invited to one of three laboratory rooms, in which they either collaborated online with two or more learning partners in the other laboratory rooms or worked individually on three problem cases. Learning partners did not meet or know each other before the experiment. The overall 72 participants were randomly assigned to one of the four experimental conditions. There were 54 participants collaborating in 18 groups of three and 18 participants working individually on the same problem cases in the same learning 
environment. We randomly selected one participant out of each group of three for analysis. In this way, individual learners of different learning arrangements were compared, and a balanced design was attained with nine participants in each of the four experimental conditions $(N=36)$. Randomisation of the experimental groups regarding gender, age, motivational and cognitive prerequisite was successful. Scores on a prior knowledge test were so low that it can be assumed that the participants of all experimental groups hardly had any pertinent prior knowledge on attribution theory.

\section{Procedure}

The experiment extended over several phases. After welcoming and testing the participants on learning prerequisites, such as prior knowledge, learning strategies, and interest (20 min.), participants were handed out a three-page summary of Weiner's attribution theory (1985). Participants could study this text individually for 15 minutes. The text remained in the hands of the participants during the work on the cases, but was taken from them before the post-test on knowledge acquisition. Participants were then introduced to the technical handling of the online learning environment (20 min.) before actually working together or alone on three problem cases with the help of attribution theory ( $80 \mathrm{~min}$.). The post-test and debriefing took about 30 minutes more.

\section{Material and online learning environment}

The text on Weiner's attribution theory (1985) handed out for individual study addressed the question how students attribute causes for success and failure. Causes for attributions are allocated on the dimensions of locality and stability. Depending on the individual attribution pattern, students would suffer motivational problems to uphold learning efforts, e.g. when students attribute failure to causes that are located internally and stable (such as lack of talent) their motivation to continue learning or even increase learning efforts would be severely reduced. The text furthermore contained findings on re-attribution- 
training, which may change detrimental attributions and foster beneficial attributions (Ziegler \& Heller, 2000).

Learners were to apply attribution theory to problem cases, which were developed to resemble situations that were authentic to the participants, e.g. participating in school counselling as a student teacher. The cases were sufficiently complex, including irrelevant and ambiguous information to take multiple perspectives and construct arguments and counter-arguments. One of the cases was, for instance, about a 16-year-old pupil whom the participants were to counsel as student teachers. The pupil performs badly in Mathematics and attributes this failure to a lack of talent. The parents of this pupil support this internal, stable attribution pattern, whereas the teacher attributes to lack of effort, i.e. internal, variable causes.

The problem cases were represented in text form in the online environment, in which learners could compose and post messages that were then represented in discussion threads as in standard asynchronous newsreaders. Each of the three problem cases was represented in one separate and differently coloured discussion board and could be accessed any time through an overview page.

\section{Experimental conditions}

In the scripted condition, learners had three additional input windows to construct their arguments to analyse the problem case. Each of the input windows was dedicated to one specific component of single arguments, namely claim, grounds, and qualifications (see Figure 1) according to a simplified model of argument construction by Toulmin (1958; cf. Stegmann et al., 2007). Thus, the learners were guided to specify their claims, provide at least one datum with a warrant that supports the claim, and identify at least one qualifier of the claim. By push of a button, the single argument components were then copied to the main 
text input window, which represented the message as it was going to be sent to the discussion board.

$$
\begin{aligned}
& * * * * * * * * * * * * * * * * * * * * * * \\
& \text { Insert Figure } 1 \text { about here } \\
& * * * * * * * * * * * * * * * * * * * * * *
\end{aligned}
$$

In the individual conditions, learners composed analyses in the same online learning environment with the possibility to post and review analyses in the discussion boards. All participants were instructed to post a final analysis for each of the three cases. In the collaborative conditions, participants were additionally instructed to discuss the problem cases together.

\section{Operationalisation of the dependent variables}

The dependent variables of the study were process and outcome variables of individual and collaborative online learning. One out of the three problem case discussions on the pupil with difficulties in Maths - was selected for analysis and respectively, the process measures refer to participants' discussions of this one case. With respect to processes, five student helpers segmented the contributions of the participants into propositional units with an inter-rater agreement of $85 \%$. With the help of a multi-dimensional coding scheme of argumentative knowledge construction (Weinberger \& Fischer, 2006), the five student helpers categorised each unit with respect to its formal quality of argument construction, i.e. the frequency of warranted and qualified claims, to indicate learners' argumentative elaboration of the learning material (Cohen's $\kappa=.70$ ). For instance, warranted arguments such as "As the student says he is not talented, he is attributing to internal stable causes" display a higher formal quality of argument construction as unwarranted statements such as "The student is plain lazy". On another dimension we analysed the same units of analysis regarding the content quality of arguments, i.e. the adequate application of specific 
theoretical concepts to the problem case, as an indicator for task performance (Cohen's $\kappa=$ .89). For instance, in arguments such as "As the student says he is not talented, he is attributing to internal stable causes", the learner adequately relates specific theoretical concepts ("attributing to internal stable causes") to specific case information ("As the student says he is not talented"), whereas "The student is plain lazy" is an inadequate analysis against the background of attribution theory, which is not about analysis of actual phenomena, but a cognitive theory on attributions as for example in "The teacher is thinking the students is lazy". The range of task aspects, which represents the impact of distribution of content-based roles, was measured by the number of different applications of relations between concepts and case information that were constructed by individual or collaborative learners. Each specific concept-case relation appearing within learners' discourses and analyses was counted only once, regardless whether the same concept-case relation reappeared. Reappearance of concept-case relations typically points towards more thorough analysis, e.g. through learning partners reformulating specific concept-case relations, rather than mere repetition. The range of task aspects score was calculated for learners in the individual learning arrangement and the randomly selected learners in the collaborative learning arrangement. Moreover, scores were aggregated on a group level to indicate the range of task aspects that were covered within each group of learners in the collaborative condition.

In a pen and paper post-test, all learners were to analyse another problem case with the help of attribution theory individually. Equivalent to the process analyses, the analyses of the learners were segmented (84\% inter-rater agreement) and coded regarding domainspecific, application-related knowledge (Cohen's $\kappa=.84$ ), i.e. we measured the extent to which learners were individually able to apply the specific theoretical concepts to a transfer problem case adequately. With respect to argumentative knowledge, participants were tested to recall argument components such as claim, ground, and qualification, and to transfer and 
apply this argumentative knowledge when constructing grounded and qualified claims on another topic, namely smoking. Two trained coders rated argumentative knowledge by analysing which argument components learners could recall and apply (Cohen's $\kappa=.83$ ).

To enable comparison of the variables with different scales, figures based on z-scores in addition to raw score tables will be given.

Results

With regard to RQ1 on learning processes, we first tested the effects of the script and the learning arrangement on argumentative elaboration, task performance, and range of task aspects using a MANOVA. The outcomes of the MANOVA show that the script has a large effect, Pillai's Trace $=.46, F(2,31)=13.02, p<.001, \eta_{p}{ }^{2}=.46$. Neither the learning arrangement, Pillai's Trace $=.01, F(2,31)=0.16, n$. s., nor the combination of script and learning arrangement, Pillai's Trace $=.13, F(2,31)=2.28, n$. s., has significant effects.

A discriminant analysis shows that there are three significant variates to which all three process variables contribute (argumentative elaboration of the learning material, task performance, and range of task aspects; see Table 1).

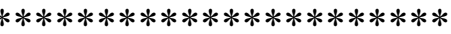

Insert Table 1 about here

$* * * * * * * * * * * * * * * * * * * * * *$

The fact that the process variables have different positive or negative weights regarding each variate indicates that the multivariate effects can be explained by these differences between the process variables. Apart from marked differences between scripted and unscripted learners regarding variate 1 and between individual and collaborative learners regarding variate 2 , the group centroids identify a difference regarding variate 3 between unscripted individual learners (.39) together with scripted collaborative learners (.26) on one hand and scripted individual learners (-.21) together with unscripted collaborative learners (- 
.44) on the other. Unscripted individual learners show the best task performance and scripted collaborative learners the highest degree of argumentative elaboration (see Figure 2).

Univariate between-subjects tests show that the script increases argumentative elaboration as was hypothesised, $F(1,32)=5.00, p=.03, \eta_{p}{ }^{2}=.14$, simultaneously reducing task performance equally in line with prior assumptions, $F(1,32)=5.15, p=.03, \eta_{p}{ }^{2}=.14$. Although this holds true for both individual and collaborative learners, interaction effects indicate that the script particularly reduces task performance of individual learners, $F(1,32)=$ $4.32, p=.05, \eta_{p}{ }^{2}=.12$. Analysis of the interaction of script and learning arrangement shows a tendency towards the script particularly facilitating argumentative elaboration of collaborative learners, $F(1,32)=3.20, p=.08, \eta_{p}{ }^{2}=.09$. These findings are in line with the assumptions that scripts are particularly beneficial for groups of learners in reducing process losses. No main effect of the learning arrangement can be found, neither for argumentative elaboration, $F(1,32)=0.25, n$. s., nor for task performance, $F(1,32)=0.01, n . s$.

$* * * * * * * * * * * * * * * * * * * * * *$

Insert Figure 2 about here

Furthermore, the script decreases the range of task aspects that are being covered as was hypothesised, $F(1,32)=3.99, p=.05, \eta_{p}{ }^{2}=.11$. There is no main effect of the learning arrangement, $F(1,32)=0.03, n$. $s$. There is, however, an interaction effect, $F(1,32)=4.28, p$ $=.05, \eta_{p}{ }^{2}=.12$, showing that the script is especially detrimental in individual learning arrangements with respect to the range of task aspects that learners could cover as is in line with earlier assumptions (see Table 2). The same pattern of effects shows when analysing the range of task aspects covered by the whole groups of three with respect to the main script effect, $F(1,32)=7.30, p=.01, \eta_{p}{ }^{2}=.19$, the (lack of) influence of the learning arrangement, $F(1,32)=1.87, n . s$. , and the interaction effect, $F(1,32)=7.67, p=.01, \eta_{p}{ }^{2}=.19$. 
As depicted in Figure 2, the script facilitates argumentative elaboration, but is detrimental for task performance as was hypothesised. The same is true for the range of task aspects being covered (as is shown in Table 2). Particularly individual learners suffer from the negative script effects on task performance and range of task aspects, whereas unscripted individual learners perform well in solving the task and do not cover less task aspects than entire groups of learners.

Collaborative learners, in contrast, benefit from the script. Scripted collaborative learners argumentatively elaborate the learning material beyond levels of unscripted and individual learning. Different from individual learning, collaborative learning does not suffer from the script regarding task performance and range of task aspects. The descriptive statistics show that the groups of three learners covered about 1.6 times as many task aspects as the individual group members, which indicates that distribution of content-based roles has effectively taken place in the small groups of learners. Groups paralleled unscripted individual learners regarding range of task aspects, which indicates that there was no specific true group task advantage in this respect.

Regarding learning outcomes (RQ2), we first tested the effects of the script and the learning arrangement on acquisition of argumentative knowledge and domain-specific knowledge using a MANOVA. The MANOVA shows a significant interaction of script and learning arrangement, Pillai's Trace $=.18, F(2,31)=3.50, p=.04, \eta_{p}{ }^{2}=.18$. Moreover, MANOVA shows that the script has a large effect, Pillai's Trace $=.48, F(2,31)=14.29, p<$ $.001, \eta_{p}{ }^{2}=.48$. The learning arrangement, Pillai's Trace $=.10, F(2,31)=0.16, n . s$., has no significant multivariate effect. 
A discriminant analysis shows that there are two significant variates to which the two outcome variables domain-specific and argumentative knowledge contribute to different extents (see Table 3).

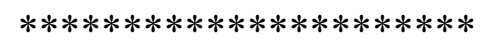

Insert Table 3 about here

This suggests that both domain-specific and argumentative knowledge can be treated as separate dependent variables. Variate 1, which is highly congruent to argumentative knowledge, differentiates between scripted and unscripted learners. The group centroids are positive for scripted individual (.48) and collaborative learners (1.32) and negative for unscripted individual (-1.04) and collaborative learners (-.76). Regarding variate 2, to which domain-specific knowledge is the largest contributor, the group centroids show that unscripted individual learners (.39) together with scripted collaborative learners (.46) are markedly different from scripted individual learners (-.68) and unscripted collaborative learners (-.17).

Univariate between-subject tests show an interaction effect on domain-specific knowledge, $F(1,32)=7.14, p=.01, \eta_{p}{ }^{2}=.18$, which indicates that groups acquire more domain-specific knowledge than individual learners when supported with the script. Furthermore, the tests show that the script has no effect on domain-specific knowledge, $F(1$, $32)=0.26, n$. s. Also, no effect of the learning arrangement on acquisition of domain-specific knowledge, $F(1,32)=1.43, n$. s., can be found. Regarding argumentative knowledge, no interaction effect can be found, $F(1,32)=0.41, n$. $s$. The script substantially facilitates acquisition of argumentative knowledge as was hypothesised (see Figure 3 and Table 4), $F(1$, $32)=29.45, p=.00, \eta_{p}{ }^{2}=.48$. No effect of the learning arrangement on acquisition of argumentative knowledge, $F(1,32)=2.55, n$. s., can be found. 


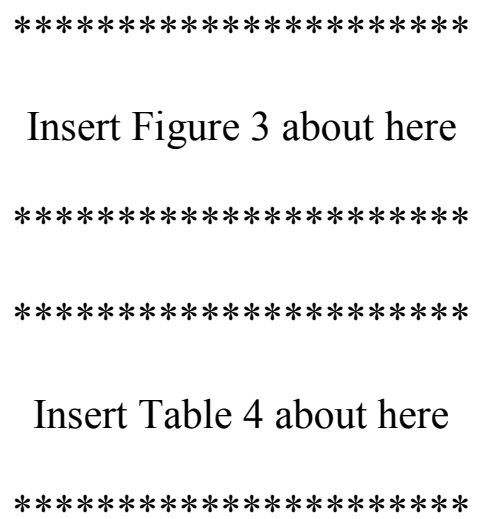

With regard to the descriptive statistics on individual knowledge acquisition, scripted collaborative learners acquired more domain-specific and argumentative knowledge than learners of any other condition. The analyses indicate that the script makes a difference regarding learning outcomes and as expected facilitates argumentative knowledge. Groups acquire more domain-specific knowledge than individual learners only when supported with the script. Unscripted collaborative learners do not learn better than scripted individual learners; they also acquire less argumentative knowledge than unscripted individual learners.

\section{Discussion}

Argumentative knowledge construction in online learning environments bears the potential of facilitating learning beyond recall of concepts and facts (Johnson \& Johnson, 1992; Kirschner et al., 2009). Students can learn to apply knowledge and learn to argue online. This study contributes to a growing body of research showing that to tap into that potential collaborative learners need additional support such as collaboration scripts (Clark \& Sampson, 2007; De Wever et al., this issue; Ertl et al., 2006; Fischer et al., 2007; Munneke et al., 2006; O’Donnell, 1999; Pfister, 2005; Rummel \& Spada, 2007; Stegmann et al., 2007).

By comparing processes and outcomes of individual and collaborative learning we found in the specific context under investigation here that learners in unscripted groups do not acquire more domain-specific or argumentative knowledge than individual learners. AKC in collaborative online environments unfolds its potential only when learners are scaffolded 
to argumentatively elaborate the learning material (cf. Hmelo-Silver, Duncan, \& Chinn, 2007; Kirschner, Sweller, \& Clark, 2006). Scripted collaborative learners acquired more domain-specific and more argumentative knowledge than any other experimental group. This result stands out since earlier research shows that it is difficult to design scripts that facilitate both domain-general and domain-specific knowledge simultaneously (Kollar et al., 2007; Rummel \& Spada, 2007; Stegmann et al., 2007; Weinberger et al., 2005).

Collaborative learners could particularly benefit from the positive script effect on argumentative elaboration and simultaneously compensate the script demands on task performance and range of task aspects being covered. Scripted collaborative learners could effectively distribute content-based roles, cover a large range of task aspects, and draw on sound arguments from their learning partners (Fischer, 2002; Leitão, 2000). Thus, the script supported learners in harvesting the process gains and reducing the process losses accompanying learning together online (see Meijas, 2007; Strijbos et al., 2004). Individual learners, in contrast, who cannot build on their partners' contributions and distribute contentbased roles, have difficulties to perform and cover a large range of task aspects when confronted with additional script demands for formally adequate arguments.

Overall, prompting learners to elaborate their arguments by differentiating claims, data with warrants, and qualifiers helped collaborative learners in particular to elaborate their arguments without impeding distribution of content-based roles: unaffected by the script's additional constraints, scripted and unscripted collaborative learners could cover comparable quantities of task aspects. The results suggest that scripting collaborative learners in online learning environments is a feasible instructional approach to foster domain-specific and argumentative knowledge.

Some limitations of the study should be considered, however. First, the findings may not fully generalise to other, more experienced populations of learners since the participants 
of the study were first semester students with hardly any pertinent prior domain knowledge and little CSCL experience. Future research needs to consider how scripts interact with varying levels of prior knowledge (e.g., building on Kollar et al., 2007). Second, assumptions deriving from CSCW and respective results on processes of CSCL need to be carefully interpreted. Collaborative learners are supposed to have different orientations towards solving a task than working groups, which does not allow generalisation of the results on task performance back to CSCW contexts. Third, scripts have shown to have specific effects depending on a set of characteristics (Weinberger, Stegmann, Fischer, \& Mandl, 2007). In this respect, the results cannot be generalised in a straightforward way to other types of scripts. In this particular study, a script was being investigated, which could be applied in individual as well as in collaborative learning arrangements. It would be worthwhile to investigate the effects of scripts distributing roles on task performance, range of task aspects being covered, and knowledge acquisition. Fourth, the problem cases may be complex, but cannot be regarded as true group tasks for which collaboration of two or more learners is a sine qua non condition. Therefore, in line with Cohen (1994), advantages of collaborative learning should become even more apparent when true group tasks are being used.

Investigating scripts for genuine group tasks may clarify further how scripts need to be adapted to the needs of individual learners and how groups of learners benefit from determining their own procedures (see Clark \& Sampson, 2007). This and other studies indicate how individual and collaborative learning facilitates specific learning processes and outcomes (e.g., Kirschner et al., 2009). Furthermore, scripts can structure specific activities of learners including orchestration of individual and collaborative learning phases (Dillenbourg \& Jermann, 2007), which has been found to be particularly effective for collaborative writing scenarios (Veerman \& Treasure-Jones, 1999; Zammuner, 1995). 
Learning to argue online 27

Blending individual and collaborative activities is feasible through scripting and may facilitate AKC beyond strictly individual or collaborative scenarios. 


\section{References}

Andriessen, J., Baker, M., \& Suthers, D. (Eds.). (2003). Arguing to learn: Confronting cognitions in computer-supported collaborative learning environments. Dordrecht: Kluwer.

Asterhan, C. S., \& Schwarz, B. B. (2007). The effects of monological and dialogical argumentation on concept learning in evolutionary theory. Journal of Educational Psychology, 99, 626-639.

Baker, M. (2003). Computer-mediated argumentative interactions for the co-elaboration of scientific notions. In J. Andriessen, M. Baker, \& D. Suthers (Eds.), Arguing to learn: Confronting cognitions in computer-supported collaborative learning environments (pp. 1-25). Dordrecht: Kluwer.

Barile, A. L., \& Durso, F. T. (2002). Computer-mediated communication in collaborative writing. Computers in Human Behavior, 18, 173-190.

Clark, D. B., \& Sampson, V. (2007). Personally-seeded discussions to scaffold online argumentation. International Journal of Science Education, 29, 253-277.

Clark, D. B., Sampson, V., Weinberger, A., \& Erkens, G. (2007). Analytic frameworks for assessing dialogic argumentation in online learning environments. Educational Psychology Review, 19, 343-374.

Cohen, E. G. (1994). Restructuring the classroom: Conditions for productive small groups. Review of Educational Research, 64, 1-35.

Cohen, E. G., \& Lotan, R. A. (1995). Producing equal-status interaction in the heterogeneous classroom. American Educational Research Journal, 32, 99-120.

De Wever, B., Van Keer, H., Schellens, T., \& Valcke, M. (this issue). Roles as a structuring tool in online discussion groups: The differential impact of different roles on social knowledge construction. Computers in Human Behavior, xx, $\mathrm{xx}-\mathrm{xx}$. 
Dillenbourg, P., Baker, M., Blaye, A., \& O’Malley, C. (1995). The evolution of research on collaborative learning. In P. Reimann \& H. Spada (Eds.), Learning in humans and machines: Towards an interdisciplinary learning science (pp. 189-211). Oxford, UK: Elsevier.

Dillenbourg, P., \& Jermann, P. (2007). Designing integrative scripts. In F. Fischer, H. Mandl, J. Haake, \& I. Kollar (Eds.), Scripting computer-supported communication of knowledge: Cognitive, computational and educational perspectives (pp. 275-301). New York: Springer.

Erduran, S., \& Jiménez-Aleixandre, M. P. (Eds.). (2007). Argumentation in science education: Perspectives from classroom-based research. Dordrecht: Springer.

Ertl, B., Fischer, F., \& Mandl, H. (2006). Conceptual and socio-cognitive support for collaborative learning in videoconferencing environments. Computers \& Education, 47, 298-315.

Fischer, F. (2001). Gemeinsame Wissenskonstruktion. Analyse und Förderung in computerunterstützten Kooperationsszenarien [Collaborative knowledge construction. Analysis and facilitation in computer-supported collaborative scenarios]. Unpublished professorial dissertation, Ludwig-Maximilans-Universität, München, Germany.

Fischer, F. (2002). Gemeinsame Wissenskonstruktion: Theoretische und methodologische Aspekte [Collaborative knowledge construction: Theoretical and methodological aspects]. Psychologische Rundschau, 53, 119-134.

Fischer, F., Kollar, I., Mandl, H., \& Haake, J. M. (Eds.). (2007). Scripting computersupported collaborative learning: Cognitive, computational and educational perspectives. New York: Springer. 
Galegher, J., \& Kraut, R. E. (1990). Technology for intellectual teamwork: Perspectives on research and design. In J. Galegher, R. E. Kraut, \& C. Egido (Eds.), Intellectual teamwork: Social and technological foundations of cooperative work (pp. 1-20). Hillsdale, NJ: Lawrence Erlbaum Associates.

Goldberg, A., Russell, M., \& Cook, A. (2003). The effect of computers on student writing: A metaanalysis of studies from 1992 to 2002. Journal of Technology, Learning, and Assessment, 2(1). Retrieved April 1, 2009 from http://escholarship.bc.edu/jtla/vol2/1/

Hinsz, V. B., Tindale, R. S., \& Vollrath, D. A. (1997). The emerging conceptualization of groups as information processors. Psychological Bulletin, 121, 43-64.

Hmelo-Silver, C. E., Duncan, R. G., Chinn, C. A. (2007). Scaffolding and achievement in problem-based and inquiry learning: A response to Kirschner, Sweller, and Clark (2006). Educational Psychologist, 42, 99-107.

Hsi, S., \& Hoadley, C. M. (1997). Productive discussion in science: Gender equity through electronic discourse. Journal of Science Education and Technology, 6, 23-36.

Johnson, D. W., \& Johnson, R. T. (1992). Positive interdependence: Key to effective cooperation. In R. Hertz-Lazarowitz \& N. Miller (Eds.), Interaction in cooperative groups: The theoretical anatomy of group learning (pp. 174-199). New York: Cambridge University Press.

Kerr, N. L. (1983). Motivation losses in small groups: A social dilemma analysis. Journal of Personality and Social Psychology, 45, 819-828.

Kirschner, F., Paas, F., \& Kirschner, P. A. (2009). Individual and group-based learning from complex cognitive tasks: Effects on retention and transfer efficiency. Computers in Human Behavior, 25, 306-314.

Kirschner, P. A., Buckingham Shum, S. J., \& Carr, C. S. (2003). Visualizing argumentation: Software tools for collaborative and educational sense-making. London: Springer. 
Kirschner, P. A., Sweller, J., \& Clark, R. E. (2006). Why minimal guidance during instruction does not work: An analysis of the failure of constructivist, discovery, problem-based, experiential, and inquiry-based teaching. Educational Psychologist, 41, $75-86$.

Klimoski, R., \& Mohammed, S. (1994). Team mental model: Construct or metaphor. Journal of Management, 20, 403-437.

Kollar, I., Fischer, F., \& Slotta, J. (2007). Internal and external scripts in computer-supported collaborative inquiry learning. Learning and Instruction, 17, 708-721.

Kraut, R., Galegher, J., Fish, R., \& Chalfonte, B. (1992). Task requirements and media choice in collaborative writing. Human Computer Interaction, 7, 375-407.

Kuhn, D. (1991). The skills of argument. Cambridge, UK: Cambridge University Press.

Leitão, S. (2000). The potential of argument in knowledge building. Human Development, $43,332-360$.

Mandl, H., Gruber, H., \& Renkl, A. (1996). Communities of practice toward expertise: Social foundation of university instruction. In P. B. Baltes \& U. Staudinger (Eds.), Interactive minds: Life-span perspectives on the social foundation of cognition (pp. 394-411). Cambridge, UK: Cambridge University Press.

Marttunen, M., \& Laurinen, L. (2001). Learning of argumentation skills in networked and face-to-face environments. Instructional Science, 29, 127-153.

Meijas, R. J. (2007). The interaction of process losses, process gains, and meeting satisfaction within technology-supported environments. Small Group Research, 38, 156-194.

Munneke, L., Andriessen, J., Kanselaar, G., \& Kirschner, P. (2007). Supporting interactive argumentation: Influence of representational tools on discussing a wicked problem. Computers in Human Behavior, 23, 1072-1088. 
Nussbaum, M. E. (2008). Collaborative discourse, argumentation, and learning: Preface and literature review. Contemporary Educational Psychology, 33, 345-359.

O’Donnell, A. M. (1999). Structuring dyadic interaction through scripted cooperation. In A. M. O’Donnell \& A. King (Eds.), Cognitive perspectives on peer learning (pp. 179-196). Mahwah, NJ: Lawrence Erlbaum.

O’Donnell, A. M., \& Dansereau, D. F. (1992). Scripted cooperation in student dyads: A method for analyzing and enhancing academic learning and performance. In R. HertzLazarowitz \& N. Miller (Eds.), Interactions in cooperative groups: The theoretical anatomy of group learning (pp. 120-141). New York: Cambridge University Press.

Pfister, H.-R. (2005). How to support synchronous net-based learning discourses: Principles and perspectives. In R. Bromme, F. Hesse, \& H. Spada (Eds.), Barriers and biases in computer-mediated knowledge communication: And how they may be overcome (pp. 39-57). New York: Springer.

Quinn, C. N., Mehan, H., Levin, J. A., \& Black, S. D. (1983). Real education in non-real time: The use of electronic message systems for instruction. Instructional Science, 4 , 313-327.

Reiser, B. J. (2004). Scaffolding complex learning: The mechanisms of structuring and problematizing student work. The Journal of the Learning Sciences, 13, 273-304.

Rummel, N., \& Spada, H. (2007). Can people learn computer-mediated collaboration by following a script? In F. Fischer, H. Mandl, J. Haake, \& I. Kollar (Eds.), Scripting computer-supported communication of knowledge: Cognitive, computational and educational perspectives (pp. 39-55). New York: Springer.

Salomon G. (1993). No distribution without individuals' cognition. In G. Salomon (Ed.), Distributed cognitions: Psychological and educational considerations (pp. 111-138). New York: Cambridge University Press. 
Scardamalia, M., \& Bereiter, C. (1996). Computer support for knowledge-building communities. In T. Koschmann (Ed.), CSCL: Theory and practice of an emerging paradigm (pp. 249-268). Mahwah, NJ: Lawrence Erlbaum.

Schellens, T., \& Valcke, M. (2006). Fostering knowledge construction in university students through asynchronous discussion groups. Computers \& Education, 46, 349-370.

Schwarz, B., Neuman, Y., \& Biezuner, S. (2000). Two wrongs may make a right . . . If they argue together! Cognition and Instruction, 18, 461-494.

Slavin, R. E. (1993). Synthesis of research on cooperative learning. In A. E. Woolfolk (Ed.), Readings and cases in educational psychology (pp. 170-178). Needham Heights, MA: Allyn \& Bacon.

Stegmann, K., Weinberger, A., \& Fischer, F. (2007). Facilitating argumentative knowledge construction with computer-supported collaboration scripts. International Journal of Computer-Supported Collaborative Learning, 2, 421-447.

Strijbos, J. W., \& De Laat, M. F. (this issue). Developing the role concept for computersupported collaborative learning: An explorative synthesis. Computers in Human Behavior, $x x, \mathrm{xx}-\mathrm{xx}$.

Strijbos, J. W., Martens, R. L., Jochems, W. M. G., \& Broers, N. J. (2004). The effect of functional roles on group efficiency: Using multilevel modeling and content analysis to investigate computer-supported collaboration in small groups. Small Group Research, $35,195-229$.

Tammaro, S. G., Mosier, J. N., Goodwin, N. C., \& Spitz, G. (1997). Collaborative writing is hard to support: A field study of collaborative writing. Computer Supported Cooperative Work: The Journal of Collaborative Computing, 6, 19-51.

Toulmin, S. (1958). The uses of argument. Cambridge, UK: Cambridge University Press. 
Van Boxtel, C., Van der Linden, J., \& Kanselaar, G. (2000). Collaborative learning tasks and the elaboration of conceptual knowledge. Learning and Instruction, 10, 311-330.

Veerman, A. L. (2003). Constructive discussions through electronic dialogue. In J.

Andriessen, M. Baker, \& D. Suthers (Eds.), Arguing to learn: Confronting cognitions in computer-supported collaborative learning environments (pp. 117-143). Amsterdam:

Kluwer.

Veerman, A. L., \& Treasure-Jones, T. (1999). Software for problem solving through collaborative argumentation. In P. Coirier \& J. E. B. Andriessen (Eds.), Foundations of argumentative text processing (pp. 203-230). Amsterdam: University Press.

Voss, J. F., \& Van Dyke, J. A. (2001). Argumentation in psychology: Background comments. Discourse Processes, 32, 89-111.

Webb, N. M. (1989). Peer interaction and learning in small groups. International Journal of Educational Research, 13, 21-39.

Webb, N. M. (1993). Collaborative group versus individual assessment in mathematics: Processes and outcomes. Educational Assessment, 1, 131-152.

Weinberger, A., Ertl, B., Fischer, F., \& Mandl, H. (2005). Epistemic and social scripts in computer-supported collaborative learning. Instructional Science, 33, 1-30.

Weinberger, A., \& Fischer, F. (2006). A framework to analyze argumentative knowledge construction in computer-supported collaborative learning. Computers $\&$ Education, 46 , $71-95$.

Weinberger, A., Fischer, F., \& Mandl, H. (2003). Gemeinsame Wissenskonstruktion in computervermittelter Kommunikation: Wirkungen von Kooperationsskripts auf den Erwerb anwendungsorientierten Wissens [Collaborative knowledge construction in computer-mediated communication: Effects of collaboration scripts on acquisition of application-oriented knowledge]. Zeitschrift für Psychologie, 211, 86-97. 
Weinberger, A., Kollar, I., Dimitriadis, Y., Mäkitalo-Siegl, K., \& Fischer, F. (2009). Computer-supported collaboration scripts: Perspectives from educational psychology and computer science. In N. Balachef, S. Ludvigsen, T. De Jong, A. Lazonder, \& S. Barnes (Eds.), Technology-enhanced learning: Principles and products (pp. 155-174). Dordrecht: Springer.

Weinberger, A., \& Mandl, H. (2003). Computer-mediated knowledge communication. Studies in Communication Sciences, 3(3), 81-105.

Weinberger, A., Stegmann, K., \& Fischer, F. (2007). Knowledge convergence in collaborative learning: Concepts and assessment. Learning and Instruction, 17, 416426.

Weinberger, A., Stegmann, K., \& Fischer, F. (2008). Patterns of discourse and cognition of poor, good, and scripted online learners. In G. Kanselaar, J. Van Merriënboer, P. Kirschner, \& T. De Jong (Eds.), Proceedings of the International Conference of the Learning Sciences - ICLS 2008 (Vol. 3, pp. 346-348). Utrecht, The Netherlands.

Weinberger, A., Stegmann, K., Fischer, F., \& Mandl, H. (2007). Scripting argumentative knowledge construction in computer-supported learning environments. In F. Fischer, H. Mandl, J. Haake, \& I. Kollar (Eds.), Scripting computer-supported communication of knowledge: Cognitive, computational and educational perspectives (pp. 191-211). New York: Springer.

Weiner, B. (1985). An attributional theory of achievement motivation and emotion. Psychological Review, 92, 548-573.

Yarrow, F., \& Topping, K. J. (2001). Collaborative writing: The effects of metacognitive prompting and structured peer interaction. British Journal of Educational Psychology, 71, 261-282. 
Zammuner, V. L. (1995). Individual and cooperative computer-writing and revising: Who gets the best results? Learning and Instruction, 5, 101-124.

Ziegler, A., \& Heller, K. (2000). Effects of an attribution retraining with female students gifted in physics. Journal for the Education of the Gifted, 23, 217-243. 
Figure captions

Figure 1. Interface of the scripted discussion board.

Figure 2. Z-scores of task performance and argumentative elaboration of the learning material (including means and standard deviations for each experimental group).

Figure 3. Z-scores of acquired domain-specific and argumentative knowledge (including means and standard deviations for each experimental group). 
Table 1. Discriminant analysis of the processes.

\begin{tabular}{|c|c|c|c|c|c|c|}
\hline \multirow[b]{3}{*}{ Variate } & \multirow[b]{3}{*}{ Wilks $\lambda$} & \multirow[b]{3}{*}{$d f$} & \multirow[b]{3}{*}{$p$} & \multicolumn{3}{|c|}{ Standardised canonical discriminant function coefficients } \\
\hline & & & & Argumentative & Task & Range of task \\
\hline & & & & elaboration & performance & aspects \\
\hline 1 & .334 & 9 & .00 & -1.21 & .73 & .61 \\
\hline 2 & .639 & 4 & .01 & -.10 & -1.28 & 1.62 \\
\hline 3 & .885 & 1 & .05 & -.62 & .85 & -.44 \\
\hline
\end{tabular}


Table 2. Raw scores of task performance, range of task aspects covered, and argumentative elaboration of the learning material.

Individual

Script
Collaborative

Process variable

No script

Script

No script

Task performance

$\begin{array}{lcccc}M & 2.00 & 12.11 & 7.00 & 7.44 \\ S D & 2.87 & 9.99 & 6.12 & 7.02 \\ 95 \% \mathrm{CI} & {[-2.74-6.74]} & {[7.37-16.85]} & {[2.26-11.74]} & {[2.71-12.18]}\end{array}$

Range of task aspects

$\begin{array}{lllll}M & 1.89 & 8.33 & 5.44 & 5.33 \\ S D & 2.62 & 6.60 & 4.50 & 4.44\end{array}$

$95 \% \mathrm{CI}$

$[-1.34-5.12] \quad[5.11-11.56]$

[2.12 - 8.67]

$[2.11-8.56]$

Range of task aspects

(aggregated group values)

$\begin{array}{lcccc}M & 1.89 & 8.33 & 9.22 & 8.33 \\ S D & 2.62 & 6.60 & 5.17 & 5.72 \\ 95 \% \mathrm{CI} & {[-1.67-5.45]} & {[4.78-11.89]} & {[5.67-12.78]} & {[4.78-11.89]}\end{array}$

Argumentative elaboration

of the learning material

$\begin{array}{lcccc}M & 8.44 & 7.44 & 13.56 & 4.56 \\ S D & 4.25 & 6.95 & 9.02 & 5.70 \\ 95 \% \mathrm{CI} & {[3.89-13.00]} & {[2.89-12.00]} & {[9.00-18.11]} & {[0.00-9.11]}\end{array}$


Table 3. Discriminant analysis of the outcomes.

Standardised canonical discriminant function coefficients

Variate Wilks $\lambda \quad d f \quad p \quad$ Domain-specific knowledge Argumentative knowledge

\begin{tabular}{llllll}
\hline 1 & .400 & 6 & .00 & .08 & .99 \\
2 & .807 & 2 & .03 & 1.01 & -.22 \\
\hline
\end{tabular}


Table 4. Raw scores of acquired domain-specific and argumentative knowledge.

\begin{tabular}{lcccc}
\hline & \multicolumn{2}{c}{ Individual } & \multicolumn{2}{c}{ Collaborative } \\
Process variable & Script & No script & Script & No script \\
\hline $\begin{array}{l}\text { Domain-specific } \\
\text { knowledge }\end{array}$ & & & & \\
$M$ & 2.89 & 5.00 & 6.67 & 3.56 \\
SD & 1.90 & 3.12 & 3.94 & 2.35 \\
$95 \%$ CI & {$[0.90-4.88]$} & {$[3.01-6.99]$} & {$[4.68-8.66]$} & {$[1.57-5.55]$} \\
\hline Argumentative knowledge & & & & \\
$M$ & 4.78 & 3.11 & 5.56 & 3.44 \\
SD & 1.20 & 1.45 & 0.53 & 0.73 \\
$95 \%$ CI & {$[4.07-5.49]$} & {$[2.40-3.82]$} & {$[4.85-6.27]$} & {$[2.74-4.15]$} \\
\hline
\end{tabular}


Figure 1

Michael is attributing internal
stable


Figure 2

\section{Learning Processes}

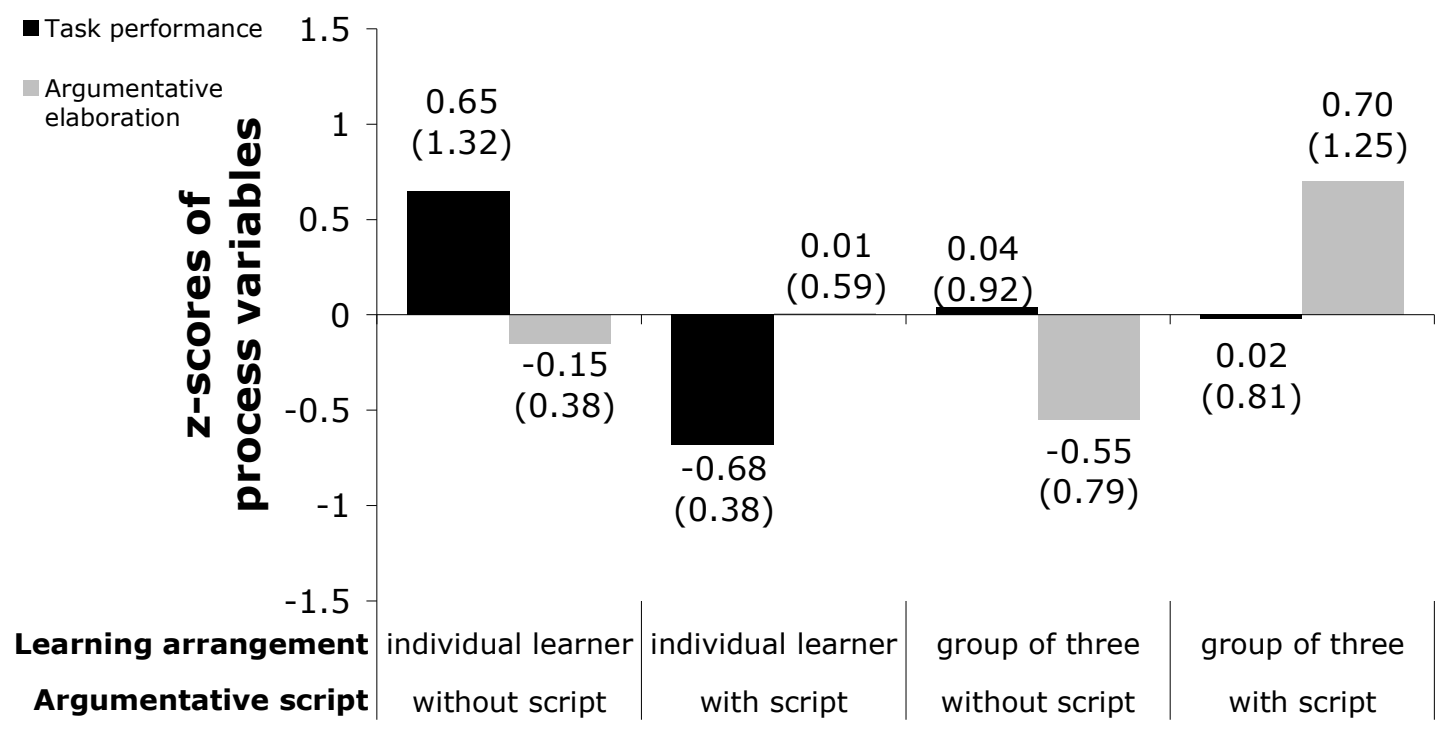


Figure 3

\section{Learning Outcomes}

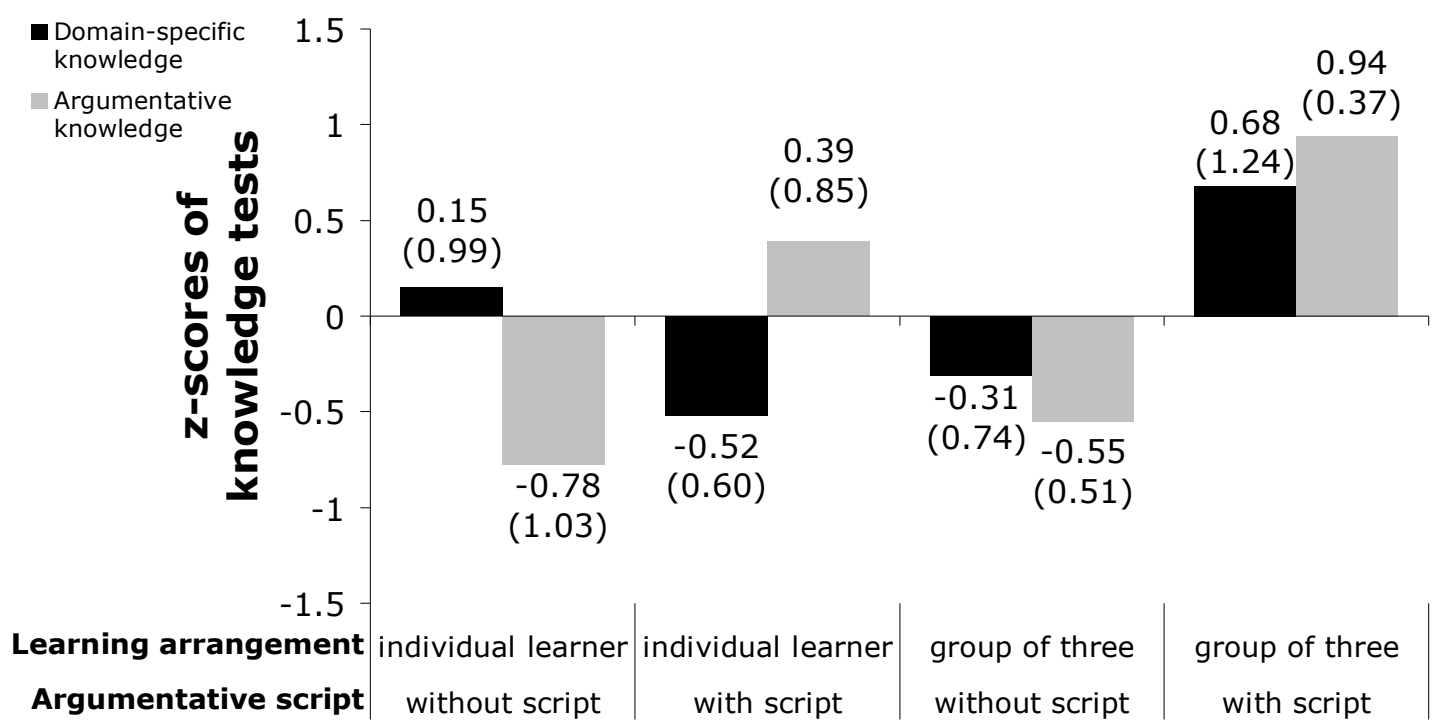

